University of Wollongong

Research Online

Faculty of Informatics - Papers (Archive)

Faculty of Engineering and Information

Sciences

$17-10-2007$

\title{
The Bullwhip effect in complex supply chains
}

I. Alony

University of Wollongong, irit@uow.edu.au

Albert Munoz Aneiros

University of Wollongong, amunoz@uow.edu.au

Follow this and additional works at: https://ro.uow.edu.au/infopapers

Part of the Physical Sciences and Mathematics Commons

\section{Recommended Citation}

Alony, I. and Munoz Aneiros, Albert: The Bullwhip effect in complex supply chains 2007.

https://ro.uow.edu.au/infopapers/647

Research Online is the open access institutional repository for the University of Wollongong. For further information contact the UOW Library: research-pubs@uow.edu.au 


\title{
The Bullwhip effect in complex supply chains
}

\author{
Abstract \\ This paper reviews the various methods of modelling the dynamics of supply chains. We then present \\ recently documented causes of the Bullwhip effect in production supply chains, and the methodologies \\ used to describe and measure the importance of these causes. We examine the limitations of these \\ methodologies and suggest a combined approach discrete event-continuous simulation modelling \\ approach to further study this phenomenon in complex production supply chains.

\section{Disciplines} \\ Physical Sciences and Mathematics

\section{Publication Details} \\ This conference paper was originally published as Alony, I, Munoz, A, The Bullwhip effect in complex \\ supply chains, International Symposium on Communications and Information Technologies ISCIT 2007, \\ 17-19 Oct, 1355-1360.
}




\title{
The Bullwhip effect in complex supply chains
}

\author{
Irit Alony ${ }^{*}$ and Albert Munoz ${ }^{\dagger}$ \\ Centre for Business Services Sciences \\ *University of Wollongong, Wollongong NSW 2522 Australia \\ Tel: +61-2-4221 3074, Fax: +61-2-4221 4170 \\ E-mail: iritalony@gmail.com \\ Centre for Business Services Sciences \\ 'University of Wollongong, Wollongong NSW 2522 Australia \\ Tel: +61-2-4221 3074, Fax: +61-2-4221 4170 \\ E-mail: am629@uow.edu.au \\ Authors in Alphabetical order
}

\begin{abstract}
- this paper reviews the various methods of modelling the dynamics of supply chains. We then present recently documented causes of the Bullwhip effect in production supply chains, and the methodologies used to describe and measure the importance of these causes. We examine the limitations of these methodologies and suggest a combined approach discrete event-continuous simulation modelling approach to further study this phenomenon in complex production supply chains.
\end{abstract}

\section{INTRODUCTION}

One of the most common problems in supply chain management is a disruption known as "the Bullwhip effect" (BWE) [1]. The disruptions are sharp oscillations in demand, amplified upstream along the supply chain. Many studies have tried to identify the causes for this phenomenon. However, most "real world" supply chains are not easy to study [2]. The causes are often interconnected and tracking down the sources of the disruption is difficult. Other than identifying the causes for the BWE, it is difficult (if not impossible) to quantify the degree to which each cause affects the supply chain. For this reason, many of the studies in this area either base their empirical results on a narrow range of causes, or study simple supply chains using simulations. However, the contributions to practitioners from such simulations are difficult to implement, since simple supply chains are rare in industry.

This study reviews the various methods of modelling production supply chains. We then present the major causes of the bullwhip effect as they were previously described in the literature, as well as, the method and supply chain complexity used to study them [3-5]. We then suggest a combined discrete-event and continuous simulation to study the phenomenon, which will enables to examine various BWE causes simultaneously, as well as quantifying their effect.

\section{SUPPLY CHAIN MODELLING}

In studying the behaviour of supply chains, the choice of simulation modelling over other analysis methodologies stems from its inherent flexibility; simulation is often regarded as a particularly powerful way to support decision making and supply chain design. In the field of supply chain management, one can use complex statistical methods and differential equations to manage simple supply chains, or use artificial intelligence (or agent based simulation) to achieve desired results. In many cases, simulation is a natural approach in studying supply chains as their complexity obstructs more traditional analytic evaluation [6-8], and agent based simulation is often geared towards the achievement of a system goal [9]. The choice of a modelling approach requires serious consideration of the needs of the project and the direction of the research to be undertaken.

In the following section we describe the various modelling approaches, their strengths and challenges. The choice of modelling approach directly affects which problem and structure can be investigated. Understanding the advantages and limitations of these approaches can aid in the selection of an approach to study the problems faced by a supply chain [7]. In the following section, three popular approaches to modelling the dynamics of supply chains present in the literature are reviewed; (A.) analytical, $(B$.$) agent based and$ (C.) simulation.

\section{A. Analytical Modelling}

In the analytical approach, the characteristics of a supply chain are derived by using mathematical theories such as probability, calculus, or linear algebra [7, 10]. Such properties have been used to understand the behaviour of a model and the affects of information sharing [e.g. 11]. However, exact evaluations of supply chain performance are very difficult if the model is driven by stochastic variables and capacity constraints. Examples of this type of modelling framework include work done by Lee and his co-authors [11] that completed work done by $[12,13]$. In this model, the underlying demand process faced by each echelon in a supply chain is a auto-correlated $\operatorname{AR}(1)$ process, meaning that the autoregressive model considers the previous value in calculating the current value. The model took the following functional form;

$$
D_{t}=d+\rho D_{t-1}+\varepsilon_{t}(1)
$$

Where $D_{t}$ is the demand process of the echelon, $d$ is the demand forecasted by the retailer in the absence of previous demand forecasts $(\mathrm{d}>0), \rho$ (slope coefficient) and $\varepsilon_{\mathrm{t}}$ (error term) are independent and identically distributed random 
variables with a mean of zero and a variance $\sigma^{2}$. Using these demand processes the orders at each echelon can be modelled using the above equation and predictions on future orders based on historical demand can be made. Typically, a supply chain is represented as a two echelon structure, a configuration that is far too simple to be compared with a real supply chain [7].

The choice of this type of modelling draws on a number of assumptions regarding the mathematical robustness of the model. Thus, while analytical models are computationally efficient, they tend to be highly simplified versions of reality in order for them to be tractable; such models can be envisaged as being restrictive in an industrial setting and are therefore only useful to gain simple insights [14].

\section{B. Agent-based Modelling}

Advances in the field of artificial intelligence (AI) have been used to investigate possible solutions to supply chain management problems in the form of multi-agent systems. An agent is an autonomous and independent computer program that is coordinated with other agents to achieve a system goal [9]. AI capabilities such as learning, reasoning and negotiation carry high value in enhancing the intelligence of a supply chain [7]. However, this research is typically concerned with the achievement of a system goal, often the optimisation of supply chain performance and lies outside the scope of this paper. In fact, in a study conducted by Kimborough and his co-authors, it was found that agents are capable of playing the Beer Game effectively. Agents are able to track demand, eliminate the Bullwhip effect, discover the optimal policies (where they are known), and find good policies under complex scenarios where analytical solutions are not available.

\section{Simulation Modelling}

The stochastic properties of the supply chain are too complex for most available analytical methods, as these methods are only able to present the optimal values for partial supply chains. A simulation can be created that addresses this limitation as it enables elaborate description of supply chain realities. Moreover, it has the potential to assessing discovery and formalisation of small parts of the social world. This allows humans to discover the consequences of their actions on a supply chain's performance.

The beer distribution game is a role-playing simulation of an industrial production and distribution system developed at MIT to introduce students of management to the concepts of economic dynamics and computer simulation. The game is played on a board which portrays the production and distribution of beer. Each player represents a brewery in a supply chain consisting of four sectors; retailer, wholesaler, distributor and factory. At each stage between the players there are shipping delays and order receiving delays, representing the time required to receive, process, ship, and deliver orders [1].

Sterman [1] used the beer game to study the individual behaviour on the generation of macrodynamics from microstructure of a simplified supply chain in a common managerial context (i.e. buying, selling, and inventory management). In the game, subjects manage a simulated industrial production and distribution system where their decision making is straightforward and subjects seek to minimise total costs by managing their inventories appropriately in an environment with uncertain demand.

Sterman [1] used a sample of 48 trials (192 players) collected over four years to derive a mathematical representation of behaviour that, while far from optimal, exhibits significant regularities, suggesting that subjects used similar heuristics to determine their orders. The pervasiveness and qualitative similarity of the oscillations is particularly interesting considering customer demand stayed nearly constant throughout each trial. A demonstration of this decision rule contains four parameters and is non linear. Other authors also used this method of gathering data to shed light on the behavioural causes of the bullwhip effect [15].

The applicability of the beer distribution to real world supply chains is far from ideal. When complexities of real world industries are taken into consideration (e.g. product mix, variability in transport logistics, inventory capacity constraints, etc.) many causes of the bullwhip effect are amplified, mixed or even cancelled out, and may be hard to detect in the data [2].

Simulation modelling has been successful in mimicking almost every aspect of manufacturing systems. Enterprises have discovered within a supply chain management environment how to increase customer satisfaction. but have encountered difficulties in the large number of uncertain variables with stochastic properties in the supply chain, and enormous model scales [16].

When a system is designed through simulation, the simulation model is constructed based on either a discreteevent or continuous simulation modelling method. Although it is believed that product and information flow have continuous factors in a supply chain, most supply chain problems are solved using discrete event simulation as they often are looked at with an operational focus [17]. From a programming perspective; it is easier to look at the operational side of a supply chain system as having a beginning, then a set of rules or commands that calculate discrete changes in the system over time, finalising the simulation when the predetermined time is up. If the system dynamics of a supply chain are to be simulated from a strategic level, continuous simulations are the preferred method.

A simulation model is constructed based on one of two methods. One is a discrete-event simulation method and the other a continuous method. A discrete-event simulation is a serial representation of discontinuous and instantaneous events in a supply chain. The output for the model is compared to real supply chain output. Once confidence in the base model has been established, different scenarios can be explored and measured against key performance indicators. Though product and information flow are typically considered to be continuous facets of a supply chain, most supply chain 
problems are solved using discrete-event simulation modelling in existing research [17].

However, Real supply chain management involves planning, managing and controlling flows of material, information, ownership and payment through the integration of key processes, from original suppliers through manufacturers, retailers to the end-users which produce values to the ultimate consumers $[5,9,26,33]$. Each member of the supply chain employs distinct practices and policies, inducing higher degrees of uncertainty and dynamics within a supply chain [33]. Although each process in the supply chain may be understood, their interactions are often difficult to predict [18]

A continuous-event simulation attempts to address these problems, and to capture the way variables vary continuously as time advances. It uses a systems dynamics method to represent causes, effects, and feedback loops.

The choice of a simulation software package is also important, based on the requirements of the research, a simplified simulation tool may be required if the supply chain is simple. Complex supply chains with a varied product mix subject to the judgment of individual business unit's managers on a regular basis often will require the use of sophisticated software capable of discrete and continuous simulations. The simulation software package selected for this study is Extend, by Imagine That! Inc. Extend consists of multiple blocks capable of representing functions, mathematical operations, and interactions among diverse functional blocks. The simulation model generates diverse desired outputs from selected inputs through the realization of multiple arithmetic and sequential operations [19].

Extend models are constructed with library-based iconic blocks. Each block represents a calculation or a step in a process. Each library represents a grouping of blocks with related characteristics such as discrete event, plotter, manufacturing and flow. Blocks are placed on the model worksheet and connected to create a model. There are two types of logical flows between the blocks in a model. The first type of flow is that of "items", which represent the objects that move through the system, these can be assigned attributes and priorities. The second type of logical flow is "values", which represent a single number and will change over time during the simulation run [19]. One example where this feature is particularly useful is during steps in the steelmaking process where a single unit of raw material (e.g. a slab) as produced by an upstream business unit will be used to produce several units of a different product (e.g. a coil).

The reasoning behind the selection of this software tool is in its ability to run models in discrete event and continuous modes. This is particularly valuable in the integration of feedback loops that affect a supply chain, and the software's ability to do multi-run simulations where one or more variables are set to change every run.

Simulation has rapidly become a significant methodological approach to theory development in the literature focused on strategy and organisations [20-24]. Several influential research efforts have used simulation as their primary method $[25,26]$.
The following section will describe the various causes to the bullwhip effect as they were grouped by Paik and Bagchi [4]. The sources of these causes and their limitations are discussed as well.

\section{VARIOUS CAUSES OF THE BULLWHIP EFFECT}

Paik and Bagchi [4] reviewed nine causes for BWE previously described in literature. They have listed four categories: Supply chain structure and processes, Material and information delays, Supply variability and Others. We now present these factors and discuss their sources.

\section{A. Supply Chain Structure and Processes}

Under the category Supply chain structure and processes, Paik and Bagchi listed demand forecast updating, order batching, rationing and shortage gaming, and price variations. These causes were previously discussed by Lee et al. [3]

1. Demand forecast updating - refers to the reliance on past demand information for present demand estimation. An example of demand forecast updating can be seen in Lee's [27] story of green Volvo's. In this case marketing decided to discount green cars and did not inform the supply chain managers, this created artificial demand for green cars which production quickly ramped production of green cars to meet with demand, creating greater inventory problems.

2. Order batching - Batching of orders minimizes unit ordering and production costs. However, it causes the distortion of demand information. Consequently, the supply chain upstream members receive periodical spikes in customer demand.

3. Rationing and shortage gaming - buyers' strategic ordering behaviour as a possible cause of the bullwhip effect. They explain that in an environment where there is supply shortage, buyers tend to overorder to secure resources for themselves, and suppliers tend to correct this over ordering by rationing back to smaller quantities. These two patterns of behaviour are interrelated and mutually reinforce one another. Paik and Bagchi [4] also suggest this problem is aggravated by buyers not fully considering orders that are already in place.

4. Price variations - promotions and special discounts disrupt regular buying patterns. During these events, the buyers will want to capitalize on the discount offered during a short period of time, while the manufacturer suffers an uneven production schedule, unnecessary inventory costs and distorted demand information.

The source of these results is an analytical model of a one-product two-stage supply chain, designed to capture essential aspects of the institutional structure and optimizing behaviours of members. Also, Lee et al. [3] described the conditions by which these causes were derived as an idealized situation where conditions were specifically controlled to facilitate the use of an order- 
up-to-S policy where $\mathrm{S}$ is a constant. Other conditions by which these causes were derived include:

1. Past demands are not used in forecasting future customer demand

2. No fixed order cost

3. Re-supply comes from an infinite source with a constant fixed lead time

4. Purchase cost for the product is stationary

Lee et al. relaxed each one of these conditions one at a time corresponding to each of the four causes described above. In an experimental context, a simulation of a simplified supply chain provided an excellent laboratory for theory building. However, applications to real world supply chains from this context are limited, as in most cases more than one of these conditions exist, adding complexity are organizational behaviours such as the self serving nature of individuals and lack of trust among partners in a supply chain.

\section{B. Material and Information lead times}

Paik and Bagchi [4] divided this category into material lead times and information lead times, drawing on the previous work of Towill [5]. Due to order processing, it is common for supply chains to experience delays in the transmission of information and materials, i.e. an order placed by one business unit reaches an upstream supplier after a information leadtime. Consequently, as the product is made and the order is completed and delivered, there is a processing time associated commonly known as material leadtime. As demand for materials may change from the time the order is placed to the time the material is received, difficulties arise in effective management of a supply chain. Towill's results were obtained from a simulation of a serial single-product supply chain, of three and four echelons [5, 28, 29]. These studies indicated that the delay of information between echelons was a major contributor to the bullwhip effect. However, when Paik and Bagchi [4] tested the significance of information delays as a contributor to the bullwhip effect, it was determined that information delays were not statistically significant contributor to demand amplification. Paik and Bagchi's results support the results of empirical studies by Croson and Donohue [15], and simulation studies by Dejonckheere and Chatfield [30, 31]

The conditions under which these simulations were conducted were based on previous work by Forrester [32] in which a three echelon single product supply chain was designed with fixed material and information delays. When Towill et al removed the lead times for information and material, and at the same time removed intermediaries one at a time, the bullwhip effect was significantly reduced [5]. These results have been replicated by other scholars by using the Beer Distribution Game by Sterman [33, 34].

\section{Supply Variability}

Paik and Bagchi considered machine breakdown as the only cause that induces supply variability.

5. Machine Breakdown - Forrester [35] claimed the contribution for machine breakdowns to production capacity have the potential to exaggerate demand due to over ordering in times when breakdowns are common and shortage is perceived by downstream players in the supply chain. Taylor $[36,37]$ took a more practical approach to application of demand amplification reduction techniques to the automotive industry and, unlike his predecessors in bullwhip effect research, used a real supply chain to test his theory. His research revealed that variability in machine reliability and process capability are common in real world supply chains and may be significant contributors to supply chain variability.

The characteristics of this supply chain included more dimensions than previous works, and reflected many of the complexities of an automotive supply chain

\section{Other Causes}

6. Capacity Limit - As the capacity level decreased or production delay increased, excessive swings occurred throughout the entire supply chain. If problems occur only at the start of the supply chain, that in itself does not trigger demand amplification. However, once the problems with production at this location are transmitted down the chain, this will cause erratic ordering by the downstream members and create a bullwhip effect. Forrester [32] argued that the production capacity limit might be one of the possible causes of the bullwhip effect. More recently, Paik and Bagchi [4], contended that capacity limits trigger ordering behaviour in an anticipated way. However, Paik and Bagchi found capacity limits a statistically insignificant contributor to the bullwhip effect.

7. Number of Echelons - Towill et al argued that removal of one echelon removes the amplification caused by the pipeline and inventory accumulation in that echelon [5]. They found the removal of the intermediary echelons of the Forrester supply chain reduced the bullwhip effect. Paik and Bagchi [4] found the number of echelons contributed to $17 \%$ of the bullwhip effect. Paik and Bagchi used a beer game simulation, which is a serial, single product supply chain of four echelons.

\section{E. Additional Causes}

Recent literature has uncovered several other causes of the bullwhip effect.

\section{Lead Time variability}

Chatfield et al. [31] found that the level of lead time variance exacerbates, although does not initiate, the bullwhip effect. The level of information quality was found to be the most significant factor in initiating the bullwhip effect.

Chatfield et al. [31] used a discrete event simulation similar to that used by $[38,39]$ and varied the level of lead time variation, the information quality used to update demand forecasts and whether information sharing was employed. This study was based on a simulation of a serial, single product supply chain of five echelons. 


\section{Workloads}

Akkermans and Vos [40] found workload to be a possible cause for the bullwhip effect. As higher workloads deteriorate process quality, more rework is required, which in turns results in higher workloads. This study used a modified version of the beer distribution game, as designed by Anderson and Morrice [41], to represent a service supply chain. Instead of measuring finished goods inventories, the bullwhip effect was observed through the measurement of backlogs. In this simulation, the supply chain was a modification of the beer game, called 'the mortgage game'. It simulated a serial, single product chain of four echelons. The applicability of these findings to product supply chains has not been tested.

\section{SUMMARY AND FUTURE DIRECTIONS}

The beer game and the simulations used in research to describe supply chain behaviour were never designed to handle the complexities of real world supply chains. Most supply chain modelling has been done using a simplified supply chain, with a limited number of echelons, with no branching, producing one product, and imposing a limited number of causes of the BWE. This kind of modelling can only demonstrate a limited range of causes to the BWE out of those which exist in a real supply chain.

The reasoning behind these simplifications is that BWE causes which play a role in simple supply chains are bound to be significant in complex supply chains as well. However, there is a possibility that these causes are mitigated or countered in real supply chains, either by other circumstances or by the relationships between these factors.

Studying real supply chains would assist in the discovery of causes of BWE. However, real supply chains are large, complex, and often lack reliable data regarding stock, supply movement, or delivery times. Minimising disruptions and isolating individual causes of the BWE present some serious difficulties. For studies such as this one, the model must have the ability to incorporate the detail level necessary to simulate complex supply chain behaviour and have the flexibility to mimic a dynamic environment.

What we suggest is modelling a complex supply chain, based on a real world large scale steel production corporation in Australia. This supply chain is characterised by a divergent product paths in sections where production transitions from continuous to batch production. These divergent product paths are mainly used to regulate inventory levels when physical constraints are suspected to be exceeded. The section of the supply chain of most interest is composed of 9 echelons with 4 sets of divergent product paths at three locations. Each business unit is managed using individual judgement; the complexity of the supply chain and its processes creates significant barriers to communication between the echelons. This model not only displays the effect of each activity, but also the interaction between factors as well as possible mitigation of certain causes. This architecture can be achieved using Extend.
Using the Beer game as a theoretical basis, a complex steelmaking supply chain with a vast product mix will be constructed based on data from a well established real supply chain. The supply chain is subject to managerial judgement on a daily basis, and managerial effects on the supply chain will be done in the form of ordering policies among partners, much the same as in the beer game. Managers will be provided with the necessary information much the same as in their everyday work routine and several feedback loops will be in place to ensure some sense of realistic behaviour of the supply chain will be maintained. Everyday managerial decisions impact the supply chain in one way or another. This study aims to quantify, through a variety of costing methods, the impacts of such judgement based decision in an environment similar to that of real world managers in an effort to educate managers as to the effects of how a myopic view of business performance affects the supply chain as a whole in a complex supply chain with varied product mix and production pathways. As a secondary aim, is the development of a managerial decision support system that will enable management to adopt a holistic view of the supply chain and enable improvement of current supply chain performance.

Ultimately, we propose to follow the work of Davis and Eisenhardt [18] and Repenning [22] and use simulation to develop theories on managerial behaviour in complex supply chain environments from the strategic and tactical levels of management.

\section{CONCLUSIONS}

Although the bullwhip effect has been extensively studied by various modelling techniques, these techniques suffer from many limitations. The supply chain models are often simplified to a large degree, the causes are often tested in isolation, and their sources not always stem from real supply chain settings.

A simulation architecture that is able to both view a complex supply chain and examine various causes and their affect at the same time would provide new insight to the various forces and influences in a supply chain.

\section{ACKNOWLEDGMENT}

This research has been supported by a linkage program grant from the Australian Research Council (ARC). The views expressed here are solely those of the authors. The authors wish to thank Dr. Tim Coltman, Dr Trevor Spedding, Peter Robertson and Omar Devlin for their contribution to discussions and the direction of the paper.

\section{REFERENCES}

[1] J. D. Sterman, "Modeling Managerial Behavior: Misperceptions Of Feedback In," Management Science, vol. 35, pp. $321,1989$.

[2] H. B. Hwarng, C. S. P. Chong, N. Xie, and T. F. Burgess, "Modelling a complex supply chain: understanding the effect of simplified assumptions," International Journal of Production Research, vol. 43, pp. 2829, 2005. 
[3] H. L. Lee, V. Padmanabhan, and S. Whang, "Information distortion in a supply chain: The bullwhip effect," Management Science, vol. 43, pp. 546, 1997.

[4] S. K. Paik and P. K. Bagchi, "Understanding the causes of the bullwhip effect in a supply chain," Internationa Journal of Retail and Distribution Management vol. 35, pp. 308-324, 2007.

[5] D. R. Towill, "Smoothing supply chain dynamics," International Journal of Computer Integrated Manufacturing, vol. 4, pp. 197-208, 1991.

[6] D. J. Van der Zee and J. G. A. J. Van der Vorst, "A Modeling Framework for Supply Chain Simulation: Opportunities for Improved Decision Making," Decision Sciences, vol. 36, pp. 65$95,2005$.

[7] G. Q. Huang, J. S. K. Lau, and K. L. Mak, "The impacts of sharing production information on supply chain dynamics: a review of literature," International Journal of Production Research, vol. 41, pp. 1483-1517, 2003.

[8] C. E. Ridall, S. Bennet, and N. S. Tipi, "Modeling the dynamics of supply chains," Internationa Journal of Systems Science, vol. 31, pp. 969-976, 2000.

[9] H. V. D. Parunak, R. Savit, and R. L. Riolo, "Agent-based modeling vs. Equation-based modeling: A case study and users guide," presented at Proceedings of multi-agent systems and agentbased simulation (MABS'98), 1998.

[10] D. Helbing, S. Lammer, T. Seidel, P. Seba, and T. Platkowski, "Physics, stability and dynamics of supply networks," Physical Review, vol. 70, 2004.

[11] H. L. Lee, C. S. Kut, and S. T. Christopher, "The Value of Information Sharing in a Two-Level Supply Chain," Management Science, vol. 46, pp. 626, 2000.

[12] J. A. Kahn, "Inventories and the Volatility of Production," The American Economic Review, vol. 77, pp. 667-679, 1987.

[13] B. L. Miller, "Scarf's State Reduction Method, Flexibility, and a Dependent Demand Inventory Model," Operations Research, vol. 34, pp. 83-90, 1986.

[14] P. J. Byrne and C. Heavey, "The impact of information sharing and forecasting in capacitated industrial supply chains: A case study," International Journal of Production Economics, vol. 103, pp. 420-437, 2006.

[15] R. Croson and K. Donohue, "Behavioral Causes of the Bullwhip Effect and the Observed Value of Inventory Information," Management Science, vol. 52, pp. 323, 2006.

[16] R. G. Ingalls, "The value of simulation in modeling supply chain," presented at Proceedings of the 1998 Winter Simulation Conference, Washington D.C., 1998.

[17] Y. H. Lee, M. K. Cho, S. J. Kim, and Y. B. Kim, "Supply chain simulation with discrete-continuous combined modeling," Computers \& Industrial Engineering, vol. 43, pp. 375-392, 2002.

[18] J. P. Davis, K. M. Eisenhardt, and C. B. Bingham, "Developing theory through simulation methods," Academy of Management. The Academy of Management Review, vol. 32, pp. 480-499, 2007.

[19] D. Krahl, "The Extend Simulation Environment," presented at Proceedings of the 2002 Winter Simulation Conference, San Jose, CA, 2002.

[20] R. Adner, "When are technologies disruptive? A demandbased view of the emergence of competition," Strategic Management Journal, vol. 23, pp. 667-688, 2002.

[21] T. Lant and S. Menzias, "Managing discontinuous change: A simulation study of organisational learning and entrepreneurship.," Strategic Management Journal, vol. 11, pp. 147-179, 1990.

[22] N. Repenning, "A simulation based approach to understanding the dynamics of innovation implementation.," Organization Science, vol. 13, pp. 109-127, 2002.
[23] J. W. Rivkin and N. Sigglelkow, "Balancing search and stability: Interdependencies among elements of organizational design.," Management Science, vol. 49, pp. 290-311, 2003.

[24] C. Zott, "Dynamic capabilities and the emergence of intraindustry differential firm performance: Insights from a simulation study," Strategic Management Journal, vol. 24, pp. 97-125, 2003.

[25] M. D. Cohen, J. March, and J. P. Olsen, "A garbage can model of organisational choice," Administrative Science Quarterly, vol. 17, pp. 1-25, 1972.

[26] J. March, "Exploration and exploitation in organisational learning," Organization Science, vol. 2, pp. 71-87, 1991.

[27] H. L. Lee, "Ultimate Enterprise Value Creation Using Demand-Based Management," Stanford Globat Supply Chain Management Forum, 2001.

[28] D. R. Towill, M. Naim, and J. Winker, "Industrial dynamics simulation models in the design of supply chains," International journal of physical distribution and logistics management, vol. 22, pp. 3-13, 1992.

[29] D. R. Towill and P. McCullen, "The impact of agile manufacturing on supply chain dynamics," international Journal of Logistics Management, vol. 10, pp. 83-96, 1999.

[30] J. Dejonckheere, S. M. Disney, M. Lambrecht, and D. R. Towill, "The dynamics of aggregate planning," Production Planning \& Control, vol. 14, pp. 497-516, 2003

[31] D. C. Chatfield, J. G. Kim, T. P. Harrison, and J. C. Hayya, "The Bullwhip Effect-Impact of Stochastic Lead Time, Information Quality, and Information Sharing: A Simulation Study," Production and Operations Management, vol. 13, pp. 340-353, 2004.

[32] J. W. Forrester, Industrial Dynamics. Boston, MA: MIT Press, 1961.

[33] A. V. Ackere, E. R. Larsen, and J. D. W. Morecroft, "Systems thinking and business process redesign: An application to the beer game," European Management Journal, vol. 11, pp. 412423,1993

[34] S. M. Hong-Minh, S. M. Disney, and M. Naim, "The dynamics of emergency transhipment supply chains," International Journal of Physican Distribution and Logistics Management, vol. 30, pp. 788-815, 2000.

[35] J. W. Forrester, "Industrial dynamics: a major breakthrough for decision makers," Harvard Business Review, pp. 37-66, 1958.

[36] D. Taylor, H., "Measurement and analysis of demand amplification across the supply chain," International Journal of Logistics Management, vol. 10, pp. 55, 1999.

[37] D. Taylor, H., "Demand amplification: has it got us beat?," International Journal of Physical Distribution \& Logistics Management, vol. 30, pp. 515, 2000.

[38] F. Chen, Z. Drezner, J. K. Ryan, and D. Simchi-Levi, "Quantifying the bullwhip effect in a simple supply chain: The impact of forecasting, lead times, and information," Management Science, vol. 46, pp. 436, 2000.

[39] J. Dejonckheere, S. M. Disney, M. R. Lambrecht, and D. R. Towill, "Measuring and avoiding the bullwhip effect: A control theoretic approach," European Journal of Operational Research, vol. 147, pp. 567-590, 2003

[40] H. Akkermans and B. Vos, "Amplification in Service Supply Chains: An Exploratory Case Study from the Telecom Industry," Production and Operations Management, vol. 12, pp. 204-223, 2003.

[41] E. G. Anderson and D. J. Morrice, "A Simulation Game for Service-Oriented Supply Chain Management: Does Information Sharing Help Managers with Service Capacity Decisions?," Production and Operations Management, vol. 9, pp. 1-16, 2000. 